Игры разума, или Поглощение реальности сознанием (Александр Потемкин. Соло Моно. Путешествие сознания пораженца. М.: ПоРог, 2017)

M.V. Mikhaylova, A.V. Nazarova (Moscow, Russia)

\title{
Games of Mind, or The Absorption of Reality by Consciousness (Alexander Potemkin. Solo Mono. Puteshestvie Soznania Porazhenca [Journey of the Mind of the Defeated Man]. Moscow. PoRog Publ. 2017)
}

Новый роман известного, много и плодотворно работающего на литературном поприще современного писателя Александра Потемкина представляет собой нескончаемый монолог главного героя с забавными, как всегда у автора, «несогласующимися» анкетными данными: он Федор Михайлович (реверанс Достоевскому), но при этом и Махоркин, что сразу вызывает в читательском восприятии ассоциацию с чем-то незначительным и несуразным. Да, впрочем, так оно и есть: герой не обращает внимания на свою внешность, одет в лохмотья, на ногах дырявая обувь. Питается он чем бог послал.

Роман озаглавлен «Соло Моно» (реплика в сторону мудрейшего Соломона). И это-то и есть та идея - создание существа, которое будет обладать совершенными физическими данными и повышенным интеллектом, но будет лишено обременяющей чувственности, отвлекающей от решения научных и духовных сверхзадач, недоступных нынешним людям, - которая родилась в воспаленном сознании главного героя. Она и возвышает, и отличает Махоркина от всех земных обитателей, несколько презрительно именуемых им сивомасковцами, поскольку местом его проживания является забытый Богом и людьми крохотный городок рядом с Мурманском - Сивая Маска, ведь главная их особенность (впрочем, как и всего человечества) состоит в том, что они в угоду потреблению и чувственности принесли в жертву самое ценное, чем, по его убеждению, обладает человек, - интеллект.

Роман представляет собой виртуозно выполненную автором постмодернистскую игру. Он открывается двумя обращениями: первое, авторское, - к читателям. В нем предлагается отныне измерять интеллект не распространенным способом вычисления IQ, а вкладом человека в мировую цивилизацию, основанным на из- 
мерении НIC («эйч-ай-си»), или higher intelligence consciousness, т. е. высшее выражение сознания (приводится список выдающихся личностей, в том числе и Сальвадора Дали, имя которого будет неоднократно всплывать в романе, чей показатель соответствовал 200 «эйч-ай-си». Собственно, такое предварение необходимо, чтобы понять, что вызвало к жизни идею Махоркина о создании сверхчеловека, объединяющего биоматериал и высший разум, который будет превосходить всех сивомасковцев. Второе обращение - уже от издателей, которые «льстят» тем читателям, кто все же сумеет овладеть проблематикой данной книги, для чего надо обладать НIC не меньше 100 (кто же признается в обратном?). Завершается роман благодарностью создателя произведения за прочтение и уверенностью, что прочитавший оное повысил свой интеллект во много раз.

Подобная литературная игра сразу заставляет вспомнить о летописце и издателе «Истории одного города», о публикаторе «Капитанской дочки» и многих других подобных мистификациях. Кстати, имена классиков не раз будут всплывать и в нашей рецензии, поскольку весь монолог Махоркина замешан на аллюзиях и отсылках к известным текстам, что еще раз подтверждает мысль о последовательном движении автора по постмодерниской стезе, где интертекст несет колоссальную нагрузку. В статье о творчестве А.П. Потемкина (опубл.: Простор. 2014. № 2) мы с соавтором, Н.Н. Мельниковой, выражали сомнение относительно укорененности писателя в «постмодернистском дискурсе», и мы высказали предположение, что он может покинуть это «поле» как не отвечающее уже его творческому потенциалу. Однако оказалось, что рецензенты ошиблись - и писатель не только не расстался с постмодернизмом, но, отказавшись от авантюрно-приключенческих коллизий, от сложной сюжетики, от многогеройности, приблизился к некоему мыслительному аскетизму, целиком погрузив читателя внутрь монады человеческого сознания. Но при этом осталось свойственное Потемкину обильное насыщение своих текстов отсылками к классике отечественной и зарубежной литературы и философии.

Однако постоянное обыгрывание, оборачивающееся подчас открытым пародийным переиначиванием широко известных читателю образов и мотивов, является отнюдь не игрой ради игры. Оно призвано привлечь внимание читателя и тем самым донести до него глубокую и оригинальную авторскую концепцию современного бытия. Выбор же в качестве главного героя носителя «воспаленного» сознания в этой связи понятен и логически обоснован. Взгляд погруженного в себя, являющегося «вещью в себе» Махоркина становится своеобразным инструментом остранения. Попадающие в поле его зрения привычные предметы и нормы поведения предстают с неожиданной стороны, что позволяет Потемкину заострить и гиперболизировать те стороны жизни, которые приковывают его наибольшее внимание или вызывают отторжение. А «хождение» Махоркина с севера на юг в Астрахань к заинтересовавшемуся его проектом создания Соло Моно бизнесмену Пенталкину, способному оплатить лабораторию, исследования и другие расходы (чем-то напоминающее поездку Чичикова по России и встречи его с «мертвыми душами»), дает возможность автору соединить различные сюжетные повороты, темы и авторские размышления о состоянии современного ему общества. Так проявляется этологический аспект романа (портрет общества в негероический момент его развития).

С целью акцентировать именно «внутреннюю» составляющую сюжета, автор обращается к творчеству Дали (жаль только, что в какой-то момент Махоркин и его причисляет к сивомасковцам!). Роман можно считать даже в какой-то мере 
путеводителем по музею Сальвадора Дали в Фигерасе или альбому с репродукциями его картин. Имя художника всплывает на протяжении повествования около 20 раз. И в каждом случае это указание на некую новую его картину, которая должна подтвердить или обосновать оригинальность возникающих в воображении героя образов. Причем Потемкин не злоупотребляет тем, что в современном литературоведении принято называть экфрасисом, т. е. описанием художественного творения, а только произносит название и пунктирно дает ориентиры, чтобы читатель домыслил или в крайнем случае открыл справочник и соотнес видения Махоркина с сюрреалистической практикой Дали. Стоит здесь привести названия некоторых из картин, чтобы стала ясна причудливая вязь повествования, которую на этот раз автор сделал ведущей при создании романа. Это и «Аптекарь из Фигераса, не ищущий абсолютно ничего», и «Геополитическое дитя, наблюдающее за рождением нового человека», и «Молодая девственница, развращаемая рогами собственного целомудрия», и «Постоянство памяти», и «Антропоморфный шкафчик», и «Критически-параноидальное одиночество», и «Нос Наполеона, превратившийся в беременную женщину, которая меланхолично прогуливает свою тень среди руин», и «Мадонна Рафаэля при максимальной скорости». Список можно увеличить. Но каждый мало-мальски осведомленный о наследии Дали человек сразу поймет, сколь неслучайно обращение именно к этим картинам. Ведь именно сопоставление с образами Дали говорит о воцаряющемся или уже воцарившемся на земле хаосе, уничтожающем и красоту, и человека, о всеобщем абсурде, который становится руководящим в поведении людей...

Творчество Дали, конечно же, напрямую соотносится с главной темой романа. Погружение в лабиринты собственного сознания, проникновение в сущность своего «Я» является главной движущей силой, побуждающей Махоркина к действию, что в свою очередь опять-таки отсылает к Достоевскому и обнаруженной великим русским писателем психологии «подпольного» человека. О генезисе героя можно рассуждать долго: его можно причислить к типу «книжного», «теоретизирующего» человека, широко распространенному в русской литературе, чьи попытки подчинить «живую жизнь» сухой рациональной схеме неизбежно оборачивалась поражением последней. Не будет преувеличением назвать его и «лишним» человеком, настолько он отчужден ото всех и отчаянно ищет применения своим способностям. Он, несомненно, мог бы признаться, как Печорин: «...было мне назначение высокое, потому что я чувствую в душе моей силы необъятные...».

Напомним, правда, что Махоркин усиленно настаивает на верховенстве своего сознания, отвергая подсознательные слои, однако его своеобразная сосредоточенность и постоянное подчеркивание незаинтересованности сексуальной сферой как раз и доказывает значимость для него последней. Укажем, к слову, на его поразительную осведомленность в перверсиях: он как-то невзначай упомянул об аксиллизме. Признаемся, нам пришлось заглянуть в словарь, чтобы понять, о чем идет речь, - а Махоркин в курсе! Но тут память услужливо подсказала знаменитую сцену с женскими подмышками в фильме «Андалузский пес», в создании которого прямое участие принимал Сальвадор Дали, о чем не мог не знать Махоркин, он, вероятнее всего, и фильм-то видел не раз...

Но понятно, почему все связанное с Фрейдом (имя ученого ни разу не произносится!) и сексуальными влечениями им отвергается, ведь он намерен создать свое детище хотя и из биоматериала, но лишенного либидо, ибо он убежден, что разнузданная чувственность загнала человечество в тупик. «Я никогда не хотел 
и не мог понимать, как безответные половые чувства могут подавлять сограждан больше, чем незавершенная научная идея - такая питательная среда для мозга, или нереализованный проект, даже не грандиозный. Мне представлялось это состояние грубейшей мутационной ошибкой. Эротические чувства - мерзкие гнезда в теневой стороне сознания, обильно порождающие льстецов, спесивых завистников, стяжателей, ревнивцев, они являются биоплощадкой возмужания других пороков, описанных во многих библейских книгах», - заявляет Махоркин.

Мысль о несовершенстве человеческой натуры и необходимости ее коренного преобразования уже звучала в других романах писателя. Так, один из персонажей книги «Кабала», профессор с говорящей фамилией Кошмаров (существующий лишь в сознании центрального персонажа Петра Парфенчикова и появляющийся в моменты его наркотического бреда), разработал план коренного обновления и улучшения природы русского человека, предлагая добавить в его кровь в определенном процентном соотношении немецкой, китайской, грузинской и еврейской «генетической закваски», которая поможет «пробудить у русских любовь и уважение к собственной стране, к своему народу». Эта идея не чужда и Махоркину, и он высказывает ее в одной из своих статей, рассылаемых в ведущие мировые СМИ. Однако его нацпроект, а главное - сведения, на которых он основывается, не безукоризненны с фактической точки зрения (например, не соответствуют действительности представления Махоркина о национальной политике в царской России: так, грузинские фамилии записывались в документах, иначе откуда бы мы знали о Джугашвили; украинский и белорусский языки отнюдь не выдумка лингвистов советского времени, на них писали Тарас Шевченко, Якуб Колас и Янка Купала). Вероятно, поэтому ни одна из его статей так и не опубликована, хотя Махоркин предвидит это и ничуть не удивляется отсутствию реакции мирового сообщества, считая это очередным доказательством вырождения сивомасковской породы, неспособной оценить его великие идеи.

Думается, однако, что эти и другие ошибки, противоречивые суждения (например, утверждение, что он не видит красоты окружающего мира, опровергается тем, что он почти всегда фиксирует лучи заходящего солнца на верхушках деревьев, их окрашенность, - и не только для того, чтобы узнать время; любуется Волгой) допущены автором сознательно, чтобы показать обрывочность и бессистемность знаний Махоркина (воспитанный бабушкой, он с детства много читал, регулярно посещал местные библиотечные собрания, но о его образовании ничего не известно), высмеять его самомнение и бесплодное теоретизирование, что, кстати, и подрывает доверие к нему бизнесмена Пенталкина, которому предлагается честь спонсировать дорогостоящее предприятие по созданию Соло Моно. Ведь занесшийся в своих мечтаниях необыкновенно высоко Махоркин не может обеспечить не только материальную составляющую проекта, но даже обосновать, почему требуется именно 5 миллионов долларов на всё про всё. Махоркин неоднократно подчеркивает, что с экономикой у него отношения не сложились. При этом он решительно отказывается от предложения Пенталкина включиться в работу над прибором под названием «Вижин» и таким образом заработать необходимые деньги (причем Пенталкин даже гарантирует зарплату в 3000 долларов ежемесячно, квартиру и машину) и напоминает ему про экспедицию Колумба, которую якобы совершенно безвозмездно поддержала испанская королева, поверившая малоизвестному фанатику. Этим сравнением Махоркин пытается внушить Пенталкину мысль о создании Соло Моно как о своеобразном подвиге самопо- 
жертвования, который не поддается денежной оценке, и тем самым призывает его обессмертить и свое имя. Но хотя бизнесмен признает, что именно от таких «психов», как Махоркин, исходит огромная часть цивилизационных рывков (что соответствует действительности, ведь среди новаторов могут быть и подлинные гении, а не зарвавшиеся прожектеры!), он, не видя инвестиционных перспектив, отказывается от участия в проекте. Этот несостоявшийся союз свидетельствует о катастрофическом состоянии современной российской науки, которую бросили на произвол судьбы, заставляя ученых самостоятельно искать средства для проведения исследований (намек на гранты и совместные проекты). Фраза из «Мертвых душ», обращенная к капитану Копейкину, «Ищите средств помочь себе сами» сегодня торжествует... Но тут обыгрывается намеченный в самом начале важнейший сквозной мотив романа - столкновение ума и глупости, отсылающий нас к «Похвале глупости» Эразма Роттердамского, к «Кораблю дураков» Себастьяна Бранта.

Здесь необходимо указать на мастерски выполненный портрет сегодняшнего Хозяина жизни (до этого Махоркину встретился лишь весьма жалкий Хозяин тайги): это мужчина лет сорока, «облаченный в шелковый расписной халат со стоячим воротником», сидящий «в старинном кресле, обитом бархатом», и даже расположенный у его ног пуфик - бархатный. Он немногословен, высказывается только по делу, у него отсутствующий взор, он тыкает пришедшему Махоркину, и картина Дали (NB!) не производит на него никакого впечатления. Он - c его массивной фигурой, огромным животом, широко расставляемыми при ходьбе ногами и брезгливой миной на лице - чем-то неуловимо напоминает Квашнина из купринского «Молоха». Видно, в русских капиталистах более чем за 100 лет ничего не изменилось! Под стать Пенталкину и его верные церберы, грубые, бесцеремонные, презирающие всех и вся... Но при этом проживает он на улице Советской, что ярко характеризует особенность произрастания российского капитала на фундаменте пороков прошлого! Куприн как писатель, с невероятной тонкостью воспроизводивший в своих произведениях гамму запахов, всплывет в памяти еще раз, когда будет автором явлен поразительный ольфакторный пример: «едва уловимый душок, так пахнет ушная сера, если принюхаться».

Потерпевший поражение в «сражении» с бизнесменом Махоркин задается вопросом: «А что если я сам - первая версия Соло Моно, трансграничного существа, способного существовать во всех сферах?» Надо, справедливости ради, сказать, что нечто подобное уже возникало в его воспаленном мозгу и раньше. По крайней мере все чаще он, начиная раздумывать о Соло Моно, называет его своим приемным сыном. Следовательно, он ставит себя на место его родителя. Так вырисовывается религиозно-мифологическая подоплека происходящего. Подспудно, придумав Соло Моно, Махоркин надеется разрешить сотерианскую проблему - проблему спасения человечества. Иными словами, пришествие в мир Соло Моно - это пришествие Спасителя (а сам Махоркин начинает претендовать на роль Бога-Отца!). И ему даже удается реализовать свои притязания по принципу «Мне отмщение, и Аз воздам». Обнаружив в тайге тело человека с проломленной головой, рядом с которым он находит бумажник с документами на имя некоего Геннадия Алексеевича Шляпкина, Махоркин решает найти последнего и выяснить у него подробности происшествия. Причину этого столь неожиданного для себя желания он сначала видит в любопытстве, чувстве, к его великому сожалению, еще роднящем его с сивомасковцами. Однако в действительности Махоркин 
стремится вынудить убийцу публично сознаться в содеянном преступлении. При этом он не испытывает какой-либо личной неприязни к Шляпкину, хотя тот угрожает ему расправой, слава и общественная благодарность также нисколько не интересуют героя. Вот почему, добившись от Шляпкина признания, он предоставляет решать его судьбу другим. Все внимание героя приковано к разыгрываемому им спектаклю, в котором можно увидеть проявление карнавального начала, когда нищий безумец исполняет роль Судии. Но в то же время этот эпизод можно толковать и как своеобразный имморализм Махоркина, которому чужды представления о добре и зле, и в целом этическая проблематика не очень волнует. Попреследовав и вдоволь поиздевавшись над человеком, он покидает место действия, совсем не интересуясь последствиями своих поступков. Этот эпизод, думается, отражает авторское отношение к современной российской судебно-правовой системе, полностью утратившей способность выполнять свои функции, из-за чего борющийся за восстановление справедливости человек в глазах общества выглядит помешанным, а результат судейства вообще непредсказуем.

Но, возвращаясь к мысли о мифо-религиозной составляющей романа, можно утверждать, что парадокс несостоявшейся сделки с Пенталкиным состоит именно в том, что современному миру не нужен Бог, Спаситель. Человечество отказывается от этой идеи, предпочитая легкую и комфортную жизнь. Вот почему беззаветно преданный спасительной идее человек всегда будет непонятен и чужд «деятельному миру». Так роман приобретает многоступенчатость и многослойность, становится разросшимся доказательством формулы Ницше «Бог умер». И тут в подтексте может быть услышана циничная добавка от автора: «И хорошо!» И то, что Махоркин в финале, приняв изрядную дозу «Пенталгина» и выпив настойку «Боярышника», отправляется в «иное измерение», говорит, что человечество не желает даже слышать ни о каких рецептах спасения, которые герой романа с определенной долей трезвости излагает в своих публицистических обращениях.

На включенности Махоркина в реальный мир стоит остановиться подробнее. Вопреки утверждениям героя, что окружающая действительность ему неинтересна, он не расстается с планшетом и ежевечерне читает сводку новостей. Так в его сознание проникают острейшие социально-политические темы. Узнав о трагических событиях в Кельне, Париже, Ницце, Мюнхене и других европейских городах (фиксация еще не остывших новостей делает этот роман Потемкина предельно злободневным!), он решает написать статьи, в которых поднимает наиболее значимые проблемы - беженцев, религиозного экстремизма и т. п. Здесь, кстати, вырисовывается любопытная шаткость конструкции Махоркина: отвергая религиозное сознание как заведшее человечество в тупик, как подчинившее рассудок людей одиозной догматике, он, тем не менее, апеллирует к религиозным организациям, упрекая их в том, что они не утешают и не помогают беженцам (и в этом он прав, так как голос церкви совсем не слышен в связи с потоками пересекающих границы людей). Зато очень важна оказывается его риторика, связанная с необходимостью прекратить гонку вооружений, отказаться от философии навязывания войны. Здесь он затронул крайне «болевую точку» современности - постепенное скатывание человечества на грань Третьей мировой войны, бесконечное бряцание оружием. Статьи Махоркина (кстати, воспроизводимые в тексте романа в переводах на английский, французский, китайский и другие языки) придают дополнительную окраску всему повествованию, воплощая оригинальный синтез художественного и публицистического начал, создают иллюзию включенности в 
глобальное коммуникативное пространство. Они служат, кстати, и своеобразной ретардацией повествования, замедляя его, отдаляя развязку, но при этом и приковывая внимание читателя к своеобразным «пикам» актуальности. К такому же приему можно отнести постоянно возникающее в воображении героя описание чисто технических элементов при создании Соло Моно. Это, к примеру, нанопинцет, которым будут захватываться атомы, необходимые для создания молекул, входящих в состав биомассы Соло Моно. Такие вставки поначалу кажутся тавтологичными, утомительными, и только потом начинаешь понимать, что это своеобразные «лакуны», дающие передышку читателю и одновременно показывающие «вязкость» мышления Махоркина, его «зацикленность» на одних и тех же вещах; все эти признаки точно соответствуют данным психиатрической науки: «вязкость» в психиатрии - расстройство психической деятельности (аффектов, речи, мышления), выражающееся в ее замедленности, недостаточной переключаемости и гибкости).

Другим играющим существенную роль в ткани романа началом становится визуальное изображение. Любопытно, что Потемкин прибег на этот раз к визуализации наноидей Махоркина и сопроводил свое повествование рисунками, на которых во всей красочности изображен процесс захвата и переноса атомов (выглядит это по-детски беспомощно и наивно!), что явно отсылает искушенного читателя к новаторским исканиям футуристов в деле создания книг, которые использовали любой подручный материал и рисовали картинки к собственным книгам.

Двойственное изображение героя и акцент на его пограничном психическом состоянии, причудливая и фантасмагоричная обстановка: полусказочный выморочный фон (чего стоят его приготовления ко сну, когда он «нарвал сочных листьев брусники, чтобы подложить их под голову», «линником (?! - M.M., А.Н.) устлал спальное место», а «густые ветки рябины послужили» ему покрывалом), фантазийная география путешествия Махоркина (он бесконечно долго движется по тайге (?), а потом и лесостепи, проходя пункты Зимарово, Косья, Озерный, Изъяю, Каджером, Чикшино, Пушной, Медвежьегорск, Девятины, Неверовское, Иван-Житово, затем оказывается в Астрахани, где чувствует легкий ветерок с моря (!); совмещение высоких философских вопросов и самой низкой неприкрашенной действительности, сочетающиеся с острой злободневной публицистичностью, позволяют отнести роман Александра Потемкина к жанру мениппеи. Он продолжает традицию использования литературы как орудия выявления и осмеяния человеческих пороков. И хотя его «смех» трудно назвать высоким и «очищающим», тем не менее в наличии четкой этической позиции художника (в отличие от созданного им персонажа) сомневаться не приходится. Потемкин сталкивает своего героя с разнообразными примерами человеческой девиантности, будь то участники оргии, потерявшие человеческий облик пьяницы, вообразивший себя хозяином тайги безумец или историк, каждый день разыгрывающий исторический спектакль. Своеобразной вершиной утраты интеллекта становится представительница клуба «Индивидуалис», которая стремится отринуть все достижения цивилизации и слиться с природой, т. е. вернуться в животное, доразумное состояние, что, при всем внешнем сходстве высказываемых девицей идей, разительно отлично от модели жизненного поведения, исповедуемой Махоркиным. С помощью тотальной иронии Александр Потемкин «защищает» важные для него идеи, которым грозит обесценивание в современном обществе потребления, показывая 
их непреходящее значение. И если сейчас основная масса населения не задумывается над ними, это не значит, что они утратили свою актуальность.

В новом романе Александра Потемкина нет любовной истории или лихо закрученной детективной интриги. Однако их отсутствие компенсируется путешествием «по граням внутреннего мира параноидального мыслителя». И это путешествие оказывает куда более увлекательным, чем те многочисленные и банальные перипетии, в которых оказываются герои традиционной мелодрамы или криминальной истории.

Итак, оснащенный интеллектом автора корабль повествования плывет дальше (по постмодернистским законам делаем отсылку к знаменитому фильму Ф. Феллини «А корабль плывет...»). Но все же закрадываются опасения, не сядет ли он в скором времени на мель? Не свидетельствует ли точное следование в повествовании законам постмодернизма об их обветшалости? Эвклидова геометрия в свое время была справедливо «потеснена» геометрией Лобачевского, а в данном случае вновь хочется, чтобы параллельные линии оставались параллельными, а «игры разума» не завершались безумием.

Мария Викторовна Михайлова,

докт. филол. наук

профессор

филологический факультет

МГУ имени М.В. Ломоносова

Анастасия Викторовна Назарова,

канд. филол. наук

филологический факультет

МГУ имени М.В.Ломоносова

Сведения об авторах:

Maria V. Mikhaylova,

Doctor of Philology

Professor

Philological Faculty

Lomonosov Moscow State University

mary1701@mail.ru

Anastasia V. Nazarova,

$\mathrm{PhD}$

Philological Faculty

Lomonosov Moscow State University

raznastas@gmail.com 